\title{
The IL-I7A G-197A and IL-I7F 7488T/C polymorphisms are associated with increased risk of cancer in Asians: a meta-analysis
}

This article was published in the following Dove Press journal:

Drug Design, Development and Therapy

24 September 2015

Number of times this article has been viewed

\author{
Huifen Wangl,* \\ Yanli Zhang ${ }^{1, *}$ \\ Zhaolan Liu ${ }^{2}$ \\ Yin Zhang ${ }^{3}$ \\ Hongchuan Zhao' \\ Shiyu Du' \\ 'Department of Gastroenterology, \\ China-Japan Friendship Hospital, \\ ${ }^{2}$ Center for Evidence-Based Chinese \\ Medicine, Beijing University of \\ Chinese Medicine, ${ }^{3}$ Institute of Basic \\ Research in Clinical Medicine, China \\ Academy of Chinese Medical Sciences, \\ Beijing, People's Republic of China \\ *These authors contributed equally \\ to this work
}

Background: Interleukin-17 (IL-17) is a family of emerged pro-inflammatory cytokines. The IL-17A and IL-17F are two important members of IL-17 family. Previous studies have shown that the functional IL-17A G-197A and IL-17F 7488T/C polymorphisms may contribute to susceptibility to cancer but the results were inconclusive. This meta-analysis was performed to determine the exact association between IL-17 polymorphisms and cancer risk.

Methods: Online databases were searched to identify eligible case-control studies. Pooled odds ratios (ORs) and confidence intervals (CIs) were calculated by fixed-effect models or randomeffect models. Publication bias was detected by Egger's test and Begg's test.

Results: Nine eligible case-control studies of IL-17A G-197A and seven studies of IL-17F $7488 \mathrm{~T} / \mathrm{C}$, including 3,181 cases and 4,005 controls, were identified. Pooled analysis suggested the variant IL-17A-197A allele was associated with increased risk cancer (GA/AA vs GG, $\mathrm{OR}=1.27,95 \% \mathrm{CI}: 1.15,1.41, P_{\text {heterogeneity }}=0.374$; and A vs G, OR $=1.30,95 \% \mathrm{CI}: 1.17,1.45$, $P_{\text {heterogeneity }}=0.021$ ). For IL-17F $7488 \mathrm{~T} / \mathrm{C}$, the homozygote $7488 \mathrm{CC}$ genotype significantly increased risk of cancer $\left(\mathrm{CC}\right.$ vs TC/TT, OR $=1.36,95 \% \mathrm{CI}: 0.97,1.91, P_{\text {heterogeneity }}=0.875$; and $\mathrm{CC}$ vs TT, OR $\left.=1.39,95 \% \mathrm{CI}: 1.03,1.88, P_{\text {heterogeneity }}=0.979\right)$, especially for gastric cancer.

Conclusion: The variant IL-17A-197A allele and IL-17F 7488CC genotype were associated with increased risk of cancer, especially for gastric cancer.

Keywords: interleukin-17, gene polymorphism, gastric cancer, risk, meta-analysis

\section{Introduction}

Interleukin 17 (IL-17) family is a subset of newly identified pro-inflammatory cytokines. The IL-17 family consists of six members, namely IL-17A, IL-17B, IL-17C, IL-17D, IL-17D, and IL-17F, according to structure similarity and order of discovery. ${ }^{1,2}$ The IL-17 receptor family includes five members: IL-17RA, IL-17RB, IL-17RC, IL-17RD, and IL-17RE. ${ }^{1}$ IL-17A and IL-17F are produced by T helper 17 (Th17) cells ${ }^{3}$ and are located just adjacent to each other on chromosome 6. Compared with other family members, IL-17A and IL-17F are most homologous in amino acid sequence. ${ }^{4}$ IL-17A is the fundamental member of IL-17 family. Evidence demonstrated that IL-17A could induce the expression of various pro-inflammatory genes like metalloproteinase, ${ }^{5}$ by activating pro-inflammatory signaling pathways. The IL-17A exerts its modulator function in both innate and adaptive immune systems, and plays an important role in the host defense against extracellular bacteria, protozoa, and fungi. ${ }^{6,7}$

Two common single nucleotide polymorphisms in the region of IL-17A (rs2275913, G-197A) and IL-17F (rs763780, 7488T/C) have been identified and recent studies suggest that the two functional single nucleotide polymorphisms influence the susceptibility to asthma, ${ }^{8}$ arthritis, ${ }^{9}$ and even cancer. ${ }^{10-12}$ But, the reports about IL-17A/F
Correspondence: Shiyu Du

Department of Gastroenterology, ChinaJapan Friendship Hospital, 2 Yinghua

Dongjie, Chaoyang, Beijing I00029,

People's Republic of China

Tel +861084205504

$\mathrm{Fax}+861084205504$

Email dushiyu1975@I26.com 
polymorphisms and cancer risk were controversial. Wang et $\mathrm{al}^{11}$ found IL-17A G-197A, but not IL-17F 7488T/C, polymorphism was not associated with the risk of breast cancer. On the other hand, Zhou et $\mathrm{al}^{12}$ reported both IL-17A G-197A and IL-17F 7488T/C polymorphisms were associated with the development and tumor stage of bladder cancer. It remains inconclusive whether the IL-17A G-197A and IL-17F 7488T/C polymorphisms are correlated with cancer risk or not. Therefore, we performed this meta-analysis to determine the strength of association between IL-17A G-197A and IL-17F 7488T/C polymorphisms and cancer risk by identifying and pooling eligible studies and evaluate the effect of cancer types.

\section{Materials and methods Selection of eligible studies}

To identify eligible studies, we searched PubMed, EMBASE, and Web of Science. Combination of the following key words were used: "IL17A” OR “IL17F”, "rs275913” OR “rs763780” to "IL-17” OR “interleukin 17”, "polymorphism” OR "single nucleotide polymorphism" OR "SNP", and "neoplasms" OR “cancer" OR "tumor" for Asians. No limitation was performed. The latest research was performed on April 13, 2015. Searching strategy is presented in the supplementary materials (Table S1).

\section{Inclusion and exclusion criteria}

Eligible studies were selected according to the following inclusion criteria: 1) case-control studies; 2) investigating the association between IL-17 polymorphisms (IL-17A G-197A and IL-17F 7488T/C) and risk of cancer; 3) cancer diagnosed by histopathology; and 4) available genotype frequencies. Studies that did not provide a detailed genotype frequency were excluded. Titles and abstracts of records were first screened and full text papers were further evaluated to confirm eligibility. Two reviewers (HW and HZ) extracted eligible studies independently according to the inclusion criteria. Disagreement between the two reviewers was discussed until consensus was achieved.

\section{Data extraction}

The following data were collected by two reviewers (HW and HZ) independently with a predesigned data-collection form: name of first author, year of publication, country where the study was performed, cancer types, study design, number of cases and controls, genotype frequency in cases and controls. According to the source of control, study design was defined as hospital-based or population-based. Though we defined the hospital-based and hospital-based study, the inclusion criteria and results were same. Sample size was judged with a threshold of 500 participants (large $>500$ or small <500). Chi-square test for goodness was used for the test of fit Hardy-Winberg equilibrium (HWE) in the controls and $P<0.05$ was considered as disequilibrium of HWE. Two reviewers reached consensus on each item.

\section{Statistical analysis}

Pooled odds ratios (ORs) with 95\% confidence intervals (95\% CIs) were calculated to estimate the association strength between IL-17A G-197A and IL-17F 7488T/C polymorphisms and cancer risk. Chi-square based on $\mathrm{Q}$ test was used to check the statistical heterogeneity between studies, and the heterogeneity was considered significant when $P<0.10$. The fixed-effects model (based on the MantelHaenszel method) and random-effects model (based on the DerSimonian-Laird method) were used to pool the data from different studies. The fixed-effects model was used when there was no significant heterogeneity; otherwise, the random-effects model was applied. ${ }^{13}$ The pooled ORs were achieved by calculating a weighted average of OR from each study. A 95\% CI was used for statistical significance test and a 95\% CI without 1 for OR indicating a significantly increased or reduced cancer risk. The pooled ORs were calculated for five comparison models: allele comparison (A vs a), homozygote comparison (AA vs aa), heterozygote comparison (Aa vs aa), dominant comparison (AA/Aa vs aa), and recessive comparison (AA vs Aa/aa) (A: the mutant allele, a: the wild allele; the $-197 \mathrm{~A}$ and $7488 \mathrm{C}$ alleles were considered as mutant alleles).

Subgroup analyses were conducted according to cancer types, study design, HWE, and sample size. Subgroup analysis was not performed for those subgroups with less than two studies. Meta-regression was performed to detect the source of heterogeneity. Publication bias was detected by Begg's test and the Egger' linear regression test, and a $P<0.05$ was considered significant. ${ }^{14}$ Sensitivity analyses were performed to identify individual study's effect on pooled results and test the reliability of results; all $P$-values were two-sided. All statistical analyses were calculated with STATA software (version 12.0; StataCorp, College Station, TX, USA).

\section{Results}

The process of study selection is shown in Figure 1. In summary, nine studies ${ }^{10-12,15-20}$ about IL-17A G-197A and seven studies of IL-17F $7488 \mathrm{~T} / \mathrm{C}$ were identified. The baseline 


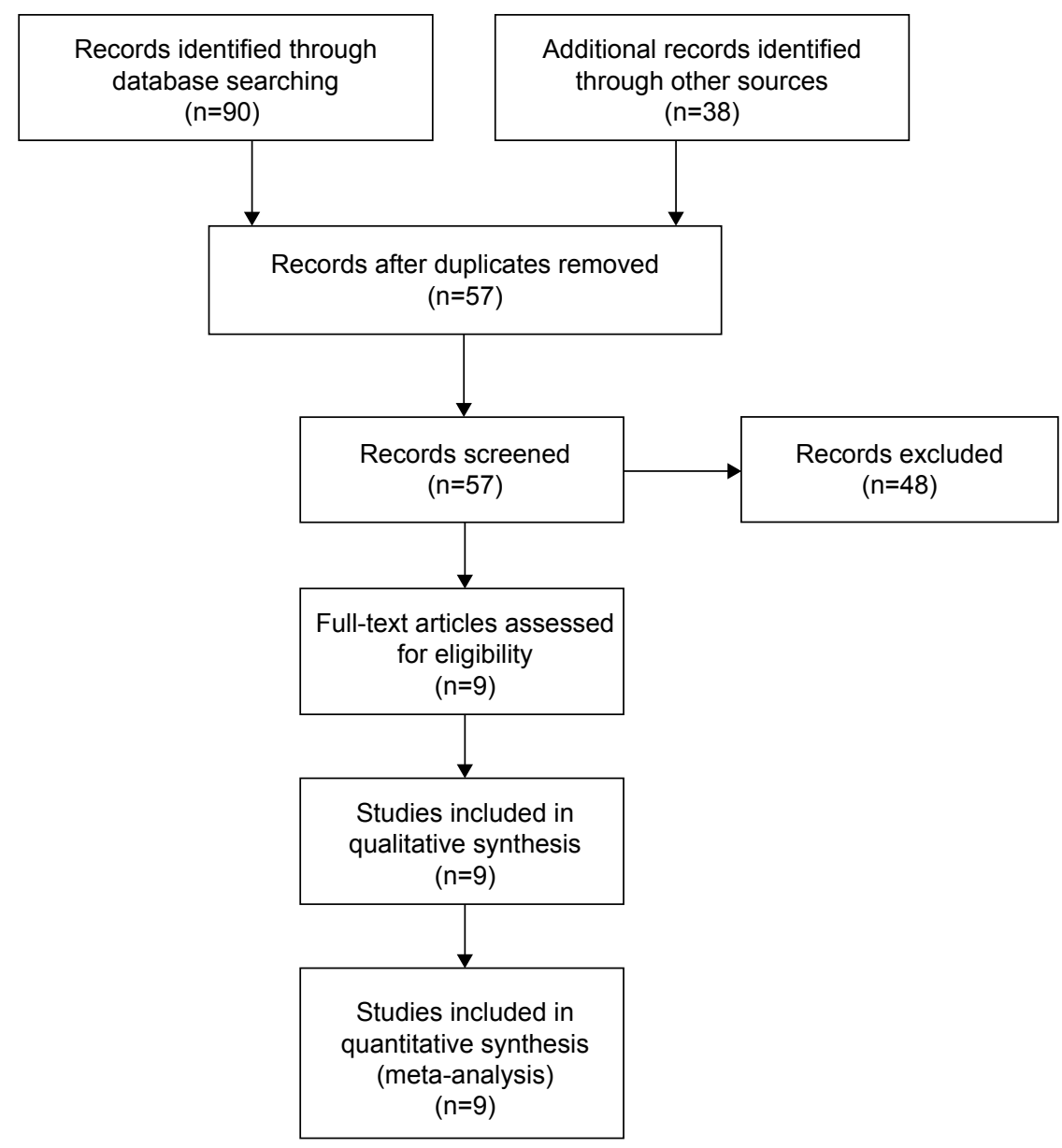

Figure I Flowchart of study selection.

characteristics of eligible studies are shown in Table 1. Of note, all eligible studies were conducted in Asia.

\section{Meta-analysis results}

A total of nine studies, involving 3,181 cases and 4,005 controls, were available for the analysis of IL-17A G-197A. By pooling eligible studies, we found carriers of the variant -197A allele were associated with a significantly increased risk of cancer (GA/AA vs GG, OR $=1.27,95 \% \mathrm{CI}$ : $1.15,1.41 ; P_{\text {heterogeneity }}=0.374$, Figure 2 ). Subgroup analyses were further conducted to evaluate the influence of predefined factors. The pooled results did not differ between different cancer types, but significant associations were most found in subgroups of population-based, large-sized studies and studies in agreement with HWE. Meta-analysis for IL-17A G-197A is shown in Table 2.

A total of seven studies, including 2,262 cases and 3,261 controls, contributed to the analysis of IL-17F $7488 \mathrm{~T} / \mathrm{C}$. Results showed that the homozygote of 7488CC genotype significantly increased susceptibility to cancer (CC vs TC/TT,
OR $=1.36,95 \%$ CI: 0.97, 1.91, $P_{\text {heterogeneity }}=0.875$; Figure 3 ). Subgroup analysis indicated the IL-17F $7488 \mathrm{~T} / \mathrm{C}$ was only associated with risk of gastric cancer but not other cancer types. HWE results affected the pooled results, but study design did not. Meta-analysis for IL-17F 7488T/C is shown in Table 3.

\section{Meta-regression analysis}

As shown in Tables 2 and 3, significant heterogeneity was observed in several comparison models, and meta-regression analysis was performed. According to meta-regression results, sample size, cancer types, and HWE were the source of heterogeneity for both IL-17A G-197A and IL-17F 7488T/C.

\section{Publication bias and sensitivity analysis}

Egger's test and Begg's test were performed to detect potential publication bias. The results suggested that no publication bias existed for the analysis IL-17A G-197A $($ Pbegg $=0.466$, Pegger $=0.975 ;$ Figure $4 \mathrm{~A})$ nor the analysis of 


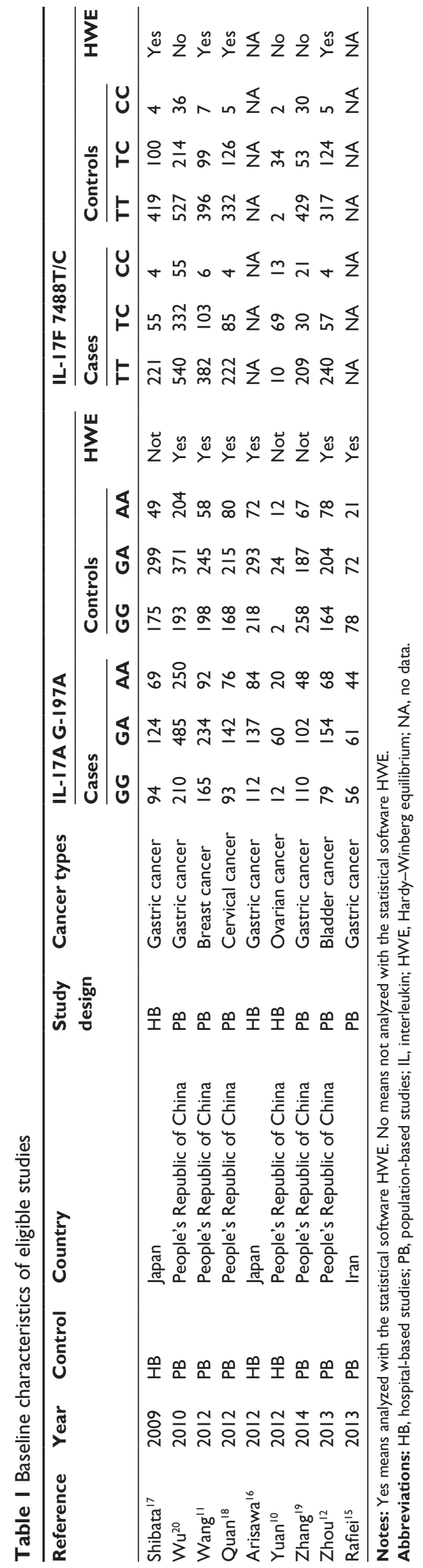

IL-17F 7488T/C (Pbegg =0.133, Pegger =0.428; Figure 4B). Individual studies' influence was determined by sensitivity analysis, which showed that the pooled results were stable and not affected by individual studies (Figures S1 and S2).

\section{Discussion}

Accumulating evidence indicates that IL-17 functions as modulator in the process of tumorigenesis and metastasis. It was found that IL-17 could induce and activate the STAT signaling pathway and promote invasion of lung cancer. ${ }^{21}$ On the other hand, IL-17 also promotes tumor invasion by modulating tumor microenvironment. ${ }^{22,23}$ Additionally, Droeser et al found that IL-17 was associated with sensitivity to platinum-chemotherapy in ovarian carcinoma. ${ }^{24}$ As a result, the expression level of IL-17 is unregulated in multiple cancers, and the level of IL-17 is correlated with progression and survival in glioblastoma and ovarian carcinoma, ${ }^{25,26}$ indicating the prognostic value of IL-17. The IL-17F 7488T/C polymorphism causes an amino acid substitution from histamine to argentine at codon 161 (H161R), which leads to a natural antagonist of wide-type IL-17. It was demonstrated by Kawaguchi et al that this functional polymorphism could influence the susceptibility to asthma. ${ }^{8}$ As for the IL-17A G-197A polymorphism, which is located in the promoter region of IL-17, it has been reported that, upon stimulation peripheral blood mononuclear cells with variant genotypes (-197AG or -197AA) secreted significantly more IL-17 than the wild type (-197GG) cells. ${ }^{27}$ This study showed that the IL-17A G-197A polymorphism could alter the promoter activity of IL-17A and cause differential production of IL-17. Taken together, these lines of evidence indicate the two polymorphisms can alter the function and production of IL-17 and it is biologically plausible that these two polymorphisms may influence susceptibility to cancer.

In the current meta-analysis, we found that both IL-17A G-197A and IL-17 7488T/C polymorphisms are associated with increased of risk of cancer. For, the IL-17A G-197A polymorphism, a significantly increased risk of cancer was found in all comparisons. While for the IL-17F 7488T/C, only carriers of the homozygote IL-17F 7488CC genotype were associated significantly increased risk of cancer and individuals with only one $7488 \mathrm{C}$ allele (the $7488 \mathrm{CT}$ genotype) showed no change cancer risk in overall analysis. One of the possible explanations is that the $7488 \mathrm{C}$ is a recessive allele, and in the presence of $7488 \mathrm{~T}$ allele, the antagonizing effect of the mutated IL-17 will be compensated by the wild-type IL-17.

Subgroup analyses were performed to evaluate the effect of cancer type, study design, sample size, and HWE. In the 




Figure 2 Forest plot of IL-17A G-197A polymorphism and cancer risk (GA/AA vs GG). Abbreviations: IL, interleukin; $\mathrm{OR}$, odds ratio; $\mathrm{Cl}$, confidence interval.

Table 2 Meta-analysis results for IL-I7A G-197A polymorphism

\begin{tabular}{|c|c|c|c|c|c|c|c|c|c|c|c|}
\hline & \multirow[t]{2}{*}{ Studies } & \multicolumn{2}{|l|}{ AA vs GG } & \multicolumn{2}{|l|}{ GA vs GG } & \multicolumn{2}{|l|}{ GA/AA vs GG } & \multicolumn{2}{|c|}{ AA vs $\mathbf{G G} / \mathbf{G A}$} & \multicolumn{2}{|l|}{ A vs $\mathbf{G}$} \\
\hline & & OR $(95 \% \mathrm{Cl})$ & Het & OR $(95 \% \mathrm{Cl})$ & Het & OR $(95 \% \mathrm{Cl})$ & Het & OR $(95 \% \mathrm{CI})$ & Het & OR $(95 \% \mathrm{Cl})$ & Het \\
\hline Total & 9 & $\begin{array}{l}I .80 \\
(1.40,2.3 I)^{*}\end{array}$ & 0.004 & $\begin{array}{l}1.12 \\
(1.01,1.25)^{*}\end{array}$ & 0.105 & $\begin{array}{l}1.27 \\
(1.15,1.4 I)^{*}\end{array}$ & 0.374 & $\begin{array}{l}1.64 \\
(1.22,2.20)^{*}\end{array}$ & $<0.00 \mathrm{I}$ & $\begin{array}{l}1.30 \\
(1.17,1.45)^{*}\end{array}$ & 0.021 \\
\hline \multicolumn{12}{|l|}{$\begin{array}{l}\text { Source } \\
\text { of controls }\end{array}$} \\
\hline PB & 6 & $\begin{array}{l}1.69 \\
(1.32,2.16)^{*}\end{array}$ & 0.045 & $\begin{array}{l}1.24 \\
(1.10,1.4 I)^{*}\end{array}$ & 0.802 & $\begin{array}{l}1.34 \\
(1.19,1.5 \mathrm{I})^{*}\end{array}$ & 0.635 & $\begin{array}{l}1.50 \\
(1.15,1.94)^{*}\end{array}$ & 0.006 & $\begin{array}{l}1.30 \\
(1.15,1.48)^{*}\end{array}$ & 0.039 \\
\hline $\mathrm{HB}$ & 3 & $\begin{array}{l}1.90 \\
(1.01,3.57)^{*}\end{array}$ & 0.037 & $\begin{array}{l}0.83 \\
(0.66,1.03)\end{array}$ & 0.527 & $\begin{array}{l}1.08 \\
(0.88,1.33)\end{array}$ & 0.319 & $\begin{array}{l}1.85 \\
(0.94,3.62)\end{array}$ & 0.003 & $\begin{array}{l}1.24 \\
(0.95,1.62)\end{array}$ & 0.055 \\
\hline \multicolumn{12}{|l|}{$\begin{array}{l}\text { Cancer } \\
\text { types }\end{array}$} \\
\hline GC & 5 & $\begin{array}{l}1.94 \\
(1.32,2.85)^{*}\end{array}$ & 0.001 & $\begin{array}{l}1.06 \\
(0.92,1.21)\end{array}$ & 0.131 & $\begin{array}{l}1.21 \\
(1.07,1.38)^{*}\end{array}$ & 0.517 & $\begin{array}{l}1.93 \\
(1.18,3.15)^{*}\end{array}$ & $<0.001$ & $\begin{array}{l}1.33 \\
(1.13,1.56)^{*}\end{array}$ & 0.013 \\
\hline Others & 4 & $\begin{array}{l}1.69 \\
(1.23,2.33)^{*}\end{array}$ & 0.175 & $\begin{array}{l}1.24 \\
(1.04,1.48)^{*}\end{array}$ & 0.257 & $\begin{array}{l}1.36 \\
(1.15,1.61)^{*}\end{array}$ & 0.247 & $\begin{array}{l}1.42 \\
(1.07,1.89)^{*}\end{array}$ & 0.139 & $\begin{array}{l}1.27 \\
(1.09,1.49)^{*}\end{array}$ & 0.15 \\
\hline \multicolumn{12}{|l|}{ HWE } \\
\hline Yes & 6 & $\begin{array}{l}1.80 \\
(1.37,2.36)^{*}\end{array}$ & 0.02 & $\begin{array}{l}1.18 \\
(1.03,1.34)^{*}\end{array}$ & 0.057 & $\begin{array}{l}1.303 \\
(1.16,1.47)^{*}\end{array}$ & 0.557 & $\begin{array}{l}1.64 \\
(1.20,2.26)^{*}\end{array}$ & $<0.001$ & $\begin{array}{l}1.32 \\
(1.16,1.49)^{*}\end{array}$ & 0.027 \\
\hline No & 3 & $\begin{array}{l}1.60 \\
(0.80,3.24)\end{array}$ & 0.01 & $\begin{array}{l}0.93 \\
(0.58,1.49)\end{array}$ & 0.356 & $\begin{array}{l}1.17 \\
(0.94,1.44)\end{array}$ & 0.137 & $\begin{array}{l}1.52 \\
(0.70,3.28)\end{array}$ & 0.001 & $\begin{array}{l}1.22 \\
(0.93,1.59)\end{array}$ & 0.068 \\
\hline \multicolumn{12}{|l|}{ Sample } \\
\hline Large & 7 & $\begin{array}{l}1.78 \\
(1.41,2.25)^{*}\end{array}$ & 0.019 & $\begin{array}{l}1.13 \\
(0.96,1.32)\end{array}$ & $0.07 I$ & $\begin{array}{l}1.26 \\
(1.14,1.40)^{*}\end{array}$ & 0.508 & $\begin{array}{l}1.68 \\
(1.24,2.28)^{*}\end{array}$ & $<0.001$ & $\begin{array}{l}1.29 \\
(1.18,1.4 I)^{*}\end{array}$ & 0.132 \\
\hline Small & 2 & $\begin{array}{l}1.03 \\
(0.10,10.27)\end{array}$ & 0.009 & $\begin{array}{l}0.93 \\
(0.39,2.20)\end{array}$ & 0.213 & $\begin{array}{l}1.36 \\
(0.90,2.06)\end{array}$ & 0.077 & $\begin{array}{l}1.32 \\
(0.30,5.69)\end{array}$ & 0.004 & $\begin{array}{l}\text { I. } 13 \\
(0.46,2.74)\end{array}$ & 0.005 \\
\hline
\end{tabular}

Note: *Statistically significant association.

Abbreviations: Het, P-value of heterogeneity; HB, hospital-based studies; PB, population-based studies; GC, gastric cancer; OR, odds ratio; Cl, confidence interval; HWE, Hardy-Winberg equilibrium. 


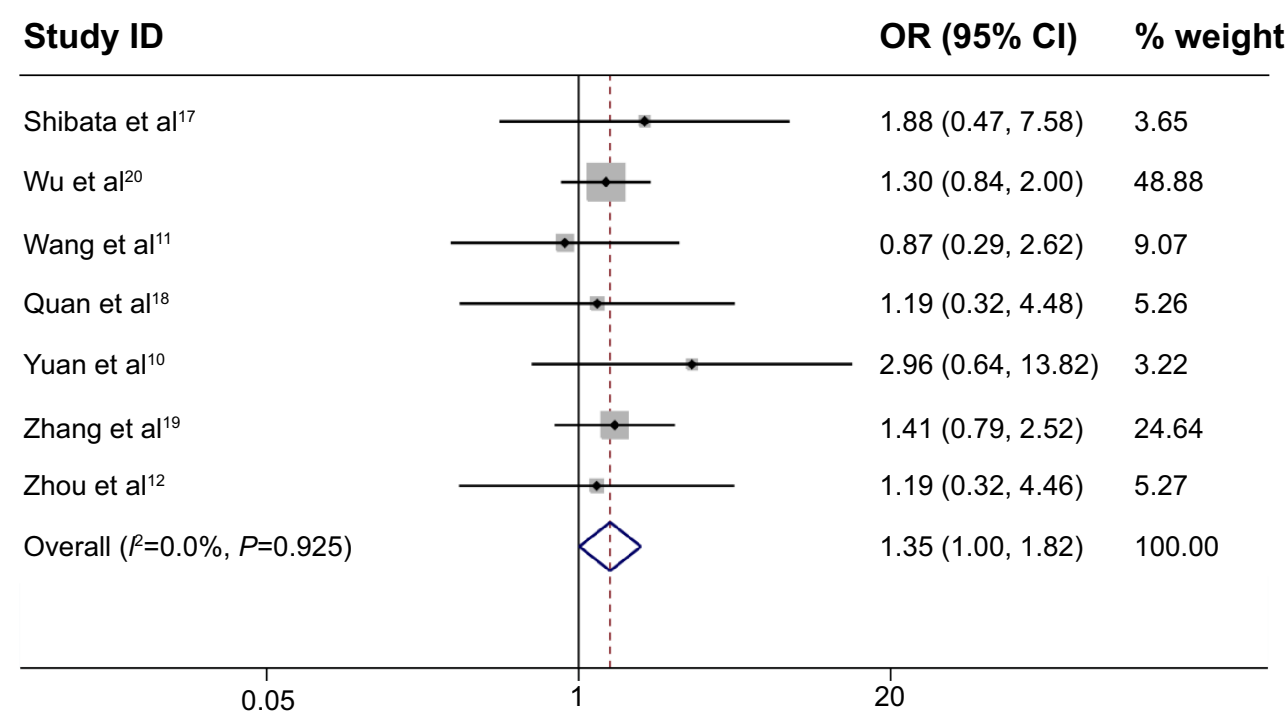

Figure 3 Forest plot of IL-I7F 7488T/C polymorphism and cancer risk (CC vs TC/TT). Abbreviations: IL, interleukin; $\mathrm{OR}$, odds ratio, $\mathrm{Cl}$, confidence interval.

sub-group analysis of cancer types, we found the IL-17F polymorphism increased risk of gastric cancer but no significant association was found for other cancers, indicating IL-17F may have a cancer-type-specific function. Additionally, it was also proposed that IL-17 production was associated with helicobacter pylori infection (IL-8 and IL-ref24) and IL-17 polymorphism could affect gastric cancer susceptibility by overproduction of IL-17 and subsequently overstimulation of immune system.

Heterogeneity was observed in some comparison models. We then performed a meta-regression analysis to identify the source of the heterogeneity and found that cancer types, study design, sample size, and HWE contributed to heterogeneity. But Begg's test and Egger's test showed that the pooled results were not biased. Sensitivity analysis also indicated that the results were stable and robust.

Actually, no previous meta-analysis about IL-17A and IL-17F has been performed. Our study made some significant contributions to new knowledge for the IL17 single nucleotide polymorphisms researches..$^{15,17,18,20}$ Our study first reported that the variant IL-17A -197A allele and IL-17F 7488CC genotype were associated with increased risk of cancer, especially for gastric cancer. As genomewide association studies is a powerful tool to determine the association between gene polymorphisms and cancer risk; we have searched the databases and no genome-wide association studies reported significant association between IL-17A or IL-17F polymorphism and cancer risk. Limitations of this

Table 3 Meta-analysis results for IL- I7F 7488T/C polymorphism

\begin{tabular}{|c|c|c|c|c|c|c|c|c|c|c|c|}
\hline & \multirow{2}{*}{$\begin{array}{l}\text { Number } \\
\text { of Studies }\end{array}$} & \multicolumn{2}{|l|}{ CC vs TT } & \multicolumn{2}{|l|}{ TC vs TT } & \multicolumn{2}{|l|}{ TC/CC vs TT } & \multicolumn{2}{|l|}{ CC vs TT/TC } & \multicolumn{2}{|l|}{ C vs T } \\
\hline & & OR $(95 \% \mathrm{Cl})$ & Het & OR $(95 \% \mathrm{Cl})$ & Het & OR $(95 \% \mathrm{Cl})$ & Het & OR $(95 \% \mathrm{Cl})$ & Het & OR $(95 \% \mathrm{CI})$ & Het \\
\hline Total & 7 & $1.39(1.03,1.88)^{*}$ & 0.979 & $1.02(0.78,1.33)$ & 0.001 & $1.05(0.82,1.35)$ & 0.001 & $1.35(1.00,1.82)^{*}$ & 0.925 & $1.08(0.90,1.30)$ & 0.009 \\
\hline \multicolumn{12}{|l|}{ Cancer } \\
\hline \multicolumn{12}{|l|}{ types } \\
\hline GC & 3 & $1.49(1.06,2.10)^{*}$ & 0.937 & $1.29(1.00,1.65)^{*}$ & 0.18 & $1.33(1.09,1.64)^{*}$ & 0.24 & $1.36(0.97,1.91)$ & 0.875 & $1.32(1.15,1.5 \mathrm{I})^{*}$ & 0.466 \\
\hline Others & 4 & $1.04(0.53,2.05)$ & 0.983 & $0.85(0.61,1.19)$ & 0.059 & $0.87(0.64,1.18)$ & 0.081 & $1.32(0.70,2.46)$ & 0.65 & $0.93(0.75,1.15)$ & 0.174 \\
\hline \multicolumn{12}{|l|}{ HWE } \\
\hline Yes & 4 & I.I5 (0.6I, 2.17) & 0.868 & $0.92(0.71,1.19)$ & 0.071 & $0.93(0.73,1.19)$ & 0.08 & $1.18(0.62,2.21)$ & 0.87 & $0.95(0.77,1.17)$ & 0.133 \\
\hline No & 3 & $1.47(1.04,2.07)^{*}$ & 0.989 & $1.29(0.89,1.88)$ & 0.176 & $1.38(1.06,1.79)^{*}$ & 0.254 & $1.41(1.00,1.97)^{*}$ & 0.598 & $1.34(1.17,1.55)^{*}$ & 0.635 \\
\hline \multicolumn{12}{|l|}{$\begin{array}{l}\text { Source of } \\
\text { controls }\end{array}$} \\
\hline PB & 5 & $1.37(1.00,1.87)^{*}$ & 0.917 & $1.04(0.76,1.43)$ & 0.001 & $1.06(0.79,1.44)$ & $<0.001$ & $1.27(0.93,1.74)$ & 0.963 & $1.09(0.83,1.45)$ & 0.923 \\
\hline $\mathrm{HB}$ & 2 & $1.69(0.52,5.42)$ & $0.77 \mid$ & $0.90(0.46,1.77)$ & 0.251 & $1.00(0.6 \mathrm{I}, \mathrm{I} .6 \mathrm{I})$ & 0.295 & $2.39(0.86,6.64)$ & 0.664 & $1.07(0.84,1.37)$ & 0.002 \\
\hline
\end{tabular}

Note: *Significant association.

Abbreviations: OR, odds ratio; $\mathrm{Cl}$, confidence interval; Het, P-value of heterogeneity; $\mathrm{HB}$, hospital-based studies; PB, population-based studies; GC, gastric cancer; HWE, Hardy-Winberg equilibrium. 


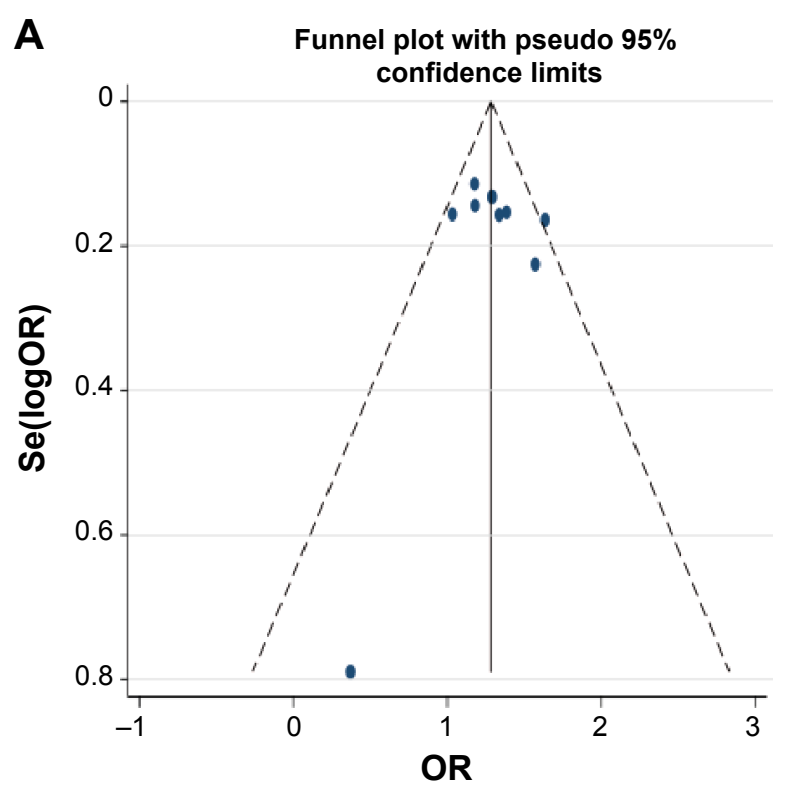

Figure 4 Funnel plots of IL-I7A G-I97A (A) and IL-I7F 7488T/C (B) polymorphisms. Abbreviations: IL, interleukin; OR, odds ratio.

meta-analysis should be noted. First, number of eligible studies was relatively small. Given limited number of studies, subgroup analyses for common cancer types was unavailable. In this meta-analysis, only subgroup analysis for gastric cancer was performed. Second, due to lack of individual data, we could not analyze the effect of other confounding factors, like smoking status, living habits, and so on.

\section{Conclusion}

In this meta-analysis, we pooled 3,181 cases and 4,005 controls and found that carriers of the variant IL-17A-197A allele and IL-17F 7488CC genotype were associated with increased risk of cancer, especially for gastric cancer.

\section{Acknowledgments}

This study was granted by China-Japan Friendship Hospital Youth Science and Technology Excellence Project (No. 2015QNYC-B-02) and the Research Fund of the China-Japan Friendship Hospital (No. 2014-2-MS-9).

\section{Disclosure}

The authors report no conflicts of interest in this work.

\section{References}

1. Gaffen SL. Structure and signalling in the IL-17 receptor family. Nat Rev Immunol. 2009;9:556-567.

2. Akhavanpoor M, Gleissner CA, Gorbatsch S, et al. CCL19 and CCL21 modulate the inflammatory milieu in atherosclerotic lesions. Drug Des Devel Ther. 2014;8:2359-2371.

3. McGeachy MJ, Cua DJ. Th17 cell differentiation: the long and winding road. Immunity. 2008;28:445-453.

\section{B \\ Funnel plot with pseudo $95 \%$}

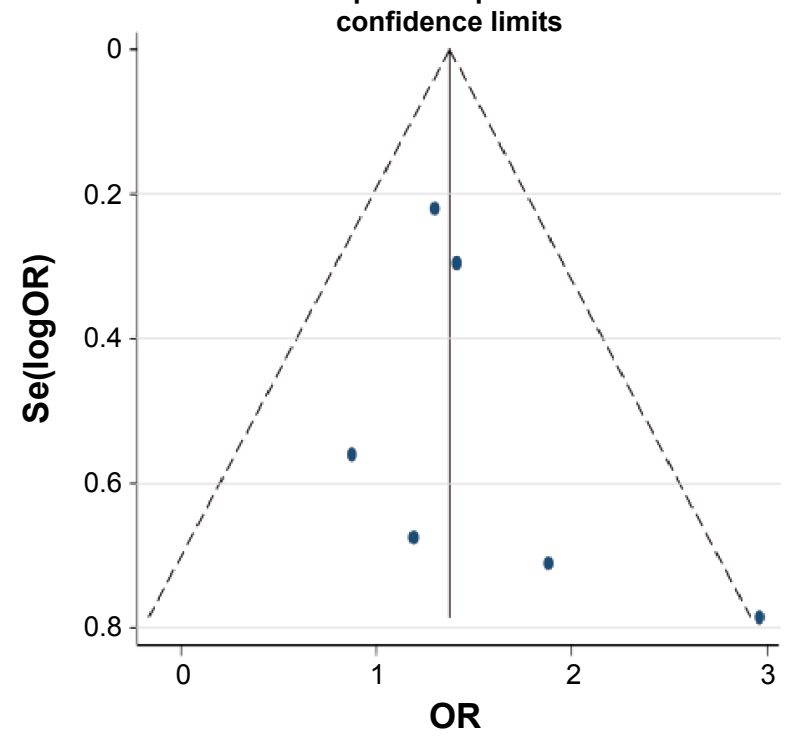

4. Iwakura Y, Ishigame H, Saijo S, Nakae S. Functional specialization of interleukin-17 family members. Immunity. 2011;34:149-162.

5. Zhu S, Qian Y. IL-17/IL-17 receptor system in autoimmune disease: mechanisms and therapeutic potential. Clin Sci. 2012;122:487-511.

6. LeibundGut-Landmann S, Gross O, Robinson MJ, Osorio F, Slack EC. Syk- and CARD9-dependent coupling of innate immunity to the induction of T helper cells that produce interleukin 17. Nat Immunol. 2007;8: 630-638.

7. Acosta-Rodriguez EV, Rivino L, Geginat J, et al. Surface phenotype and antigenic specificity of human interleukin 17-producing T helper memory cells. Nat Immunol. 2007;8:639-646.

8. Kawaguchi M, Takahashi D, Hizawa N, et al. IL-17F sequence variant (His161 Arg) is associated with protection against asthma and antagonizes wild-type IL-17F activity. J Allergy Clin Immunol. 2006;117: 795-801.

9. Nordang GB, Viken MK, Hollis-Moffatt JE, et al. Association analysis of the interleukin 17A gene in Caucasian rheumatoid arthritis patients from Norway and New Zealand. Rheumatology. 2009;48:367-370.

10. Yuan Y, Hu Y, Tao K, RZ. Association analysis of IL-17A and IL-17F gene polymorphism with epithelial ovarian cancer. $J$ Hunan Normal Univ. 2012;9:21-24.

11. Wang L, Jiang Y, Zhang Y, et al. Association analysis of IL-17A and IL-17F polymorphisms in Chinese Han women with breast cancer. PLoS One. 2012;7:e34400.

12. Zhou B, Zhang P, Wang Y, et al. Interleukin-17 gene polymorphisms are associated with bladder cancer in a Chinese Han population. Mol Carcinog. 2013;52:871-878.

13. Lau J, Ioannidis JP, Schmid CH. Quantitative synthesis in systematic reviews. Ann Intern Med. 1997;127:820-826.

14. Egger M, Davey Smith G, Schneider M, Minder C. Bias in meta-analysis detected by a simple, graphical test. BMJ. 1997;315:629-634.

15. Rafiei A, Hosseini V, Janbabai G, et al. Polymorphism in the interleukin17A promoter contributes to gastric cancer. World J Gastroenterol. 2013; 19:5693-5699.

16. Arisawa T, Tahara T, Shiroeda H, et al. Genetic polymorphisms of IL17A and pri-microRNA-938, targeting IL17A 3'-UTR, influence susceptibility to gastric cancer. Hum Immunol. 2012;73:747-752.

17. Shibata T, Tahara T, Hirata I, Arisawa T. Genetic polymorphism of interleukin-17A and -17F genes in gastric carcinogenesis. Hum Immunol. 2009;70:547-551 
18. Quan Y, Zhou B, Wang Y, et al. Association between IL17 polymorphisms and risk of cervical cancer in Chinese women. Clin Dev Immunol. 2012;2012:258293.

19. Zhang X, Zheng L, Sun Y. Analysis of the association of interleukin-17 gene polymorphisms with gastric cancer risk and interaction with Helicobacter pylori infection in a Chinese population. Tumour Biol. 2014;35:1575-1580.

20. Wu X, Zeng Z, Chen B, et al. Association between polymorphisms in interleukin-17A and interleukin-17F genes and risks of gastric cancer. Int J Cancer. 2010;127:86-92.

21. Li Q, Han Y, Fei G, Guo Z, Ren T, Liu Z. IL-17 promoted metastasis of non-small-cell lung cancer cells. Immunol Lett. 2012;148: 144-150.

22. Olsson Akefeldt S, Maisse C, Belot A, et al. Chemoresistance of human monocyte-derived dendritic cells is regulated by IL-17A. PLoS One. 2013;8:e56865.
23. Hayata K, Iwahashi M, Ojima T, et al. Inhibition of IL-17A in tumor microenvironment augments cytotoxicity of tumor-infiltrating lymphocytes in tumor-bearing mice. PLoS One. 2013;8:e53131.

24. Droeser RA, Guth U, Eppenberger-Castori S, et al. High IL-17-positive tumor immune cell infiltration is indicative for chemosensitivity of ovarian carcinoma. J Cancer Res Clin Oncol. 2013;139:1295-1302.

25. Lan C, Huang X, Lin S, et al. High density of IL-17-producing cells is associated with improved prognosis for advanced epithelial ovarian cancer. Cell Tissue Res. 2013;352:351-359.

26. Cui X, Xu Z, Zhao Z, et al. Analysis of CD137L and IL-17 expression in tumor tissue as prognostic indicators for gliblastoma. Int J Biol Sci. 2013;9:134-141.

27. Chabaud M, Fossiez F, Taupin JL, Miossec P. Enhancing effect of IL-17 on IL-1-induced IL-6 and leukemia inhibitory factor production by rheumatoid arthritis synoviocytes and its regulation by Th2 cytokines. J Immunol. 1998;161:409-414. 


\section{Supplementary materials}

Table SI Searching strategy

Searching strategy for PubMed: ((interleukin- 17) OR ILI7) AND (((single nucleotide polymorphism) OR polymorphism) OR SNP) AND (((neoplasms) OR cancer) OR tumor); records identified: 32

Searching strategy for PubMed: ((interleukin-17) OR ILI7) AND (((single nucleotide polymorphism) OR polymorphism) OR SNP) AND (((neoplasms) OR cancer) OR tumor); records identified: 10

Searching strategy for Web of Science: (interleukin- 17) AND (polymorphism) AND (cancer); records identified from Web of Science: 21

Searching strategy for China National Knowledge Infrastructure: ((interleukin- 17) OR ILI7) AND (polymorphism) OR mutation) AND (tumor) OR cancer) records identified: 27

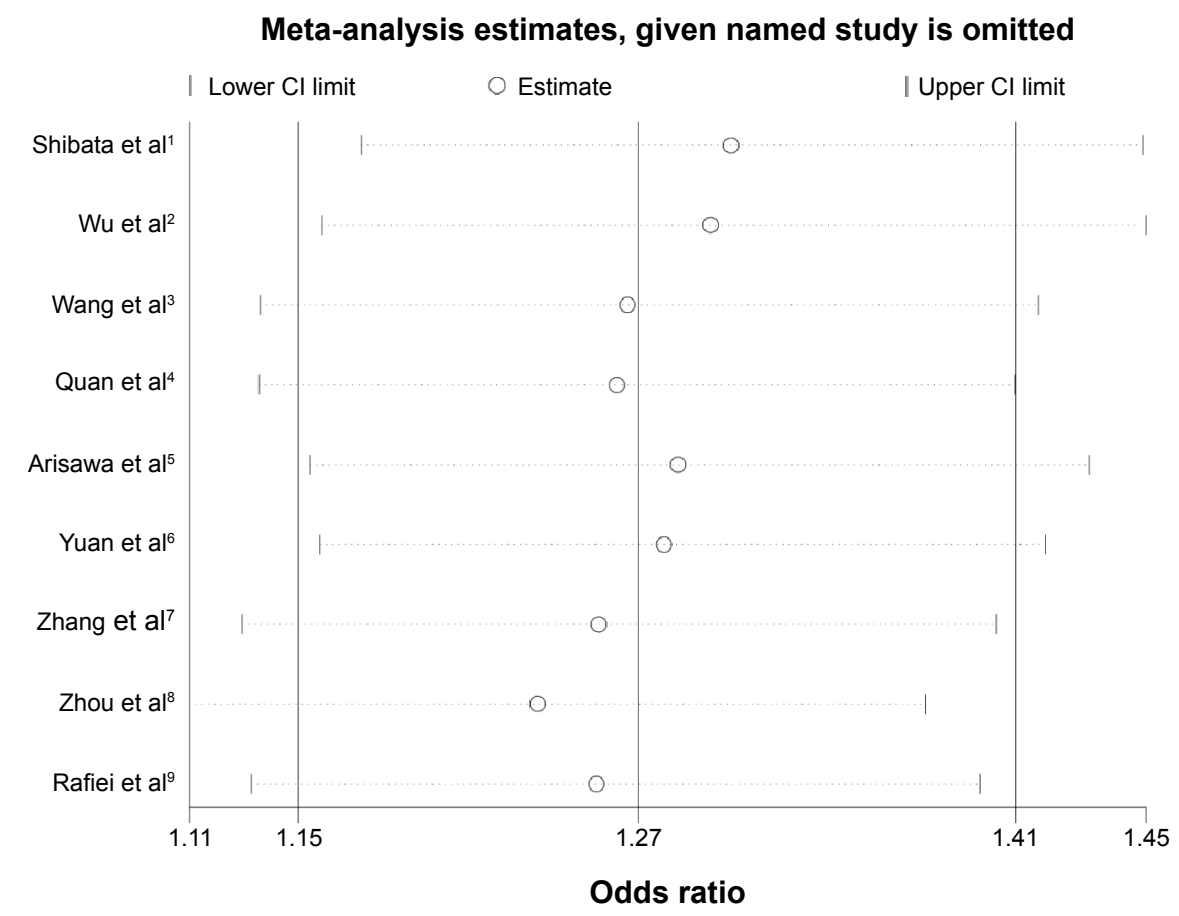

Figure SI Sensitivity analysis of IL- I7A G-197A polymorphism.

Abbreviations: IL, interleukin, $\mathrm{Cl}$, confidence interval. 
Meta-analysis estimates, given named study is omitted



Figure S2 Sensitivity analysis of IL-I7F 7488T/C polymorphism.

Abbreviations: IL, interleukin, $\mathrm{Cl}$, confidence interval.

\section{References}

1. Shibata T, Tahara T, Hirata I, Arisawa T. Genetic polymorphism of interleukin-17A and -17F genes in gastric carcinogenesis. Hum Immunol. 2009;70:547-551.

2. Wu X, Zeng Z, Chen B, et al. Association between polymorphisms in interleukin-17A and interleukin-17F genes and risks of gastric cancer. Int $J$ Cancer. 2010;127:86-92.

3. Wang L, Jiang Y, Zhang Y, et al. Association analysis of IL-17A and IL-17F polymorphisms in Chinese Han women with breast cancer. PLoS One. 2012;7:e34400.

4. Quan Y, Zhou B, Wang Y, et al. Association between IL17 polymorphisms and risk of cervical cancer in Chinese women. Clin Dev Immunol. 2012; 2012:258293

5. Arisawa T, Tahara T, Shiroeda H, et al. Genetic polymorphisms of IL17A and pri-microRNA-938, targeting IL17A $3^{\prime}$-UTR, influence susceptibility to gastric cancer. Hum Immunol. 2012;73:747-752.
6. Yuan Y, Hu Y, Tao K, RZ. Association analysis of IL-17A and IL-17F gene polymorphism with epithelial ovarian cancer. J Hunan Normal Univ. 2012;9:21-24.

7. Zhang X, Zheng L, Sun Y. Analysis of the association of interleukin-17 gene polymorphisms with gastric cancer risk and interaction with Helicobacter pylori infection in a Chinese population. Tumour Biol. 2014;35: $1575-1580$.

8. Zhou B, Zhang P, Wang Y, et al. Interleukin-17 gene polymorphisms are associated with bladder cancer in a Chinese Han population. Mol Carcinog. 2013;52:871-878

9. Rafiei A, Hosseini V, Janbabai G, et al. Polymorphism in the interleukin17 A promoter contributes to gastric cancer. World J Gastroenterol. 2013;19:5693-5699.

\section{Dovepress}

\section{Publish your work in this journal}

Drug Design, Development and Therapy is an international, peerreviewed open-access journal that spans the spectrum of drug design and development through to clinical applications. Clinical outcomes, patient safety, and programs for the development and effective, safe, and sustained use of medicines are a feature of the journal, which

has also been accepted for indexing on PubMed Central. The manuscript management system is completely online and includes a very quick and fair peer-review system, which is all easy to use. Visit http://www.dovepress.com/testimonials.php to read real quotes from published authors. 